\title{
Knowledge and Attitudes of Amateur Sports Participants Regarding the Cardiac Risks Associated With the Use of Anabolic-Androgenic Steroids
}

\author{
Dr Syed Yaseen Naqvi ${ }^{1}$, Dr Gerard Flaherty ${ }^{2}$ \\ ${ }^{1}$ Department of Internal Medicine, Pennsylvania Hospital, University of Pennsylvania, Philadelphia, USA. \\ Masters of Preventive Cardiology at National University of Ireland Galway \\ ${ }^{2}$ Director of Masters Preventive Cardiology Programme, National University of Ireland Galway, National \\ Institute for Preventive Cardiology.
}

\begin{abstract}
Background

The effect of anabolic androgenic steroids on the cardiovascular system has been well researched. However the knowledge of these effects amongst amateur sports participants has not been accurately identified. The aim of this study was to evaluate the awareness and attitudes of the cardiac risks associated with anabolic steroid use. Design: A qualitative, cross-sectional, observational study using an anonymous online questionnaire was filled out by amateur sports participants enrolled in competitive sports teams at an Irish university.

Methods: The survey contained questions to assess the participant's knowledge of cardiac effects of the use of anabolic steroids. These include its effects on blood pressure, cholesterol and potential for development of arrhythmias. The participant's attitudes, prevalence and access to the use of anabolic steroids were also investigated.

Results: A total of 267 individuals were invited to fill out the online questions. 54 responses were returned for analysis, giving a response rate of $20 \%$. One-third of respondents personally knew someone that uses anabolic steroids, however 59\% of participants were never advised about their health effects. The majority obtained their nutritional advice from Internet sites or friends. 59\% and 26\%, respectively, knew about the blood pressure and cholesterol effects of anabolic steroid use. $17 \%$ of individuals had used or had ever considered using anabolic steroids. Only 11\% were given information about performance enhancing drugs when they joined their university sports club.

Conclusions: The knowledge of the cardiac risks associated with the use of anabolic steroids amongst amateur sports participants was generally poor. Efforts must be made to educate coaches and gym facilities about the harmful effects of certain performance enhancing drugs.
\end{abstract}

Keywords: Androgenic-anabolic steroids, cardiac risks, cardiovascular system, and sports participants, performance enhancing agents

\section{Introduction}

A great amount of media attention has been directed at the use of performance-enhancing drugs (PED) to improve athletic performance over the last number of decades. Due to the competitive drive to win, a certain proportion of sports participants use PEDs to boost their gains in muscle mass and achieve an athletic advantage. The use of some of these substances may be harmful for the human body. PED include anabolic-androgenic steroids (AAS), human growth hormone, amphetamines, creatine monophosphate, erythropoietin and ephedrine. The health effects of the excessive use of these agents are documented in the medical literature $(1,2)$.

AAS is commonly used to enhance athletic performance in a varietyof sports $(3,4)$. It is estimated that between 1-3million male and female athletes in the United States alone have used AAS (5).Studies have estimated the prevalence of AAS use amongst athletes to range between $6.3 \%$ and $38.4 \%(6,7)$.

AAS are derivatives of testosterone that were synthetically produced in the late 1930s (8). AAS can be used for the treatment of a variety of diseases including male hypogonadism, cachexia secondary to acquired immunodeficiency syndrome, cancer, burns, renal and hepatic failure, and anaemia associated with leukaemia or kidney failure (9). Studies have also looked at its possible role in the treatment of chronic lung diseases (10). Apart from its medicinal uses, AAS have become a common part of athletic and weight lifting training.

AAS, more colloquially known as 'steroids', have both anabolic and androgenic effects on the body. A review article showed thattheir prolonged use in males can be associated with the following side effects gynaecomastia, impotence, infertility, testicular atrophy, baldness, acne, liver dysfunction, psychiatric disturbance and aggression(1). The cardiac effects of AAS use may include hypertension, increased low-density 
lipoprotein cholesterol, decreased highdensity lipoprotein cholesterol, increased left ventricular hypertrophy andfunction, atrial fibrillation, cardiomyopathy and myocardial infarction(1).

Hypertension is a well-known risk factor for the development of atherosclerosis. The arterial blood pressure would need to be raised for a number of years in order to produce symptoms and end-organ damage.The association between AAS use and elevated blood pressure is conflicting. A study published in the International Journal of Sports Medicine showed higher baseline systolic blood pressures in users of AAS than in non-users (11). Another similar study published a few years later showed an increase in diastolic blood pressure, which normalisedto pre-anabolic values after 6 weeks of AAS cessation (12). This increase in diastolic blood pressure was reported from 74 to $86 \mathrm{~mm} \mathrm{Hg}$ after 10 weeks of high-dose AAS use. Blood pressure measured by an ambulatory monitor over a 24-hour period showed similar results in AAS users and controls, although chronic AAS use causes an abnormal nocturnal physiological dipping (13). This is in contrast to a more recent robust study showing that AAS is not associated with significant effects on arterial structure and function, but however did affect vascular reactivity and arterial thickness(14). Another prospective study did not show statistically significant alterations in blood pressure, even in those self-administering supra-therapeutic doses of AAS for periods of up to 16 weeks(15). From these studies the medical literature on the blood pressure effects of AAS use, both short-term and long-term,is still somewhat inconclusive and conflicting.

Several studies identify a significant link between low-density lipoprotein cholesterol (LDLC) and AAS use. In a study by Lenders et al., 1988, 78 bodybuilders who were tested positive for AAS abuse showed significantly increased levels of LDL-C and decreased levels of HDL-C when compared with 13 non-steroidusing bodybuilders. These changes in lipid profile appear to develop after 9 weeks of AAS self-administration and appear to be reversible after a period of 5 months of their discontinuation (11). Elevated LDL-C is a risk factor for the development of atherosclerosis and its levels determine the treatment goal according to European dyslipidaemia guidelines, which are solely based on the cardiovascular risk score (16).

It is known that low levels of high-density lipoprotein cholesterol (HDL-C) are an independent risk factor for cardiovascular morbidity and mortality (17). There is firm research evidence that AAS use will cause reductions in HDL-C levels. An average of 52 to $78 \%$ decrease in HDL-C levels are reported depending on the HDL subtype, duration and type of AAS drug use(18). This reduction was primarily responsible due to an increase in the level of plasma hepatic triglyceride lipase activity, which also affects HDL levels (19).

Left ventricular hypertrophy $(\mathrm{LVH})$ is an established independent risk factor for cardiovascular disease (20). It has been known for many years that androgen receptors are present in cardiac myocytes and permit androgens to modulate the cardiac phenotype and produce hypertrophy by direct receptor binding (21). However studies have shown considerable physiological adaptations in cardiac muscle and function to enable an increased cardiac output and widening of the systemic arterio-venous oxygen difference. Echocardiographic findings have shown a large proportion of athletes with modest cardiac enlargement and a smaller number have demonstrated substantial increases in heart size (22). It is difficult to determine what degree of LVH is due to exercise-induced increased afterload or due to AAS abuse. A study by Karila et al. compared the effects of selfadministered AAS with and without growth hormone $(\mathrm{GH})$ on left ventricular (LV) dimensions in power athletes, which were compared to sedentary controls. The authors found a statistically significant association between LV mass and AAS dose, and this association was even greater with concomitant GH use (23). Another retrospective case control study evaluating AAS effects on LV function was performed in 14 strength-training AAS users, 11 strength-training non-users and 15 sedentary subjects.This found that the interventricular septum wall thickness was significantly larger in AAS users than non-users, however little difference was observed in posterior wall thickness. Their results concluded that there was no difference in systolic function but there were negative effects on cardiac diastolic function (24). In contrast to this, a recently published case control study looking at the echocardiographic findings in current and chronic AAS abusers showed no significant differences in LV size and function, both systolic and diastolic, in comparison to controls. The only observed difference was the diastolic size of the septum and free wall in AAS-using athletes compared to non-using athletes (25). The authors mention that long term AAS abuse does accentuate the physiologic hypertrophy observed due to engagement in long-term sport.

A study by Urhausenetal.evaluated whether or not cardiac effects of AAS use were reversible. They compared 15 weightlifters that had not been using AAS in the previous 12 months (ex-users), 17 weightlifters currently using AAS and 15 anabolic-free weightlifters. With regards to cardiac structure, they concluded that the participants still showed concentric LVH several years after discontinuation of AAS use when compared with AAS-free athletes. Blood pressure showed a mean of $140 \mathrm{mmHg}$ (SD 10mmHg) in AAS users, $130 \mathrm{mmHg}$ (SD 5mmHg) in ex-users and $125 \mathrm{mmHg}$ (SD 10mmHg) in AAS-free athletes(26).

There are concerning links, mainly via case reports and case-control studies, between AAS abuse and premature death from myocardial infarction and ventricular arrhythmia. An older study looked at the mortality of competitive Finnish power lifters who finished between $1^{\text {st }}$ and $5^{\text {th }}$ in Finnish championships during 19771982 and compared these to population controls. These powerlifters are only assumed to have used AAS due to 
the highly competitive nature of this sport. The mortality during a 12-year follow-up was $12.9 \%$ (8 out of 62 ) for the powerlifters compared to $3.1 \%$ (34 out of 1094) in the control population. This equates to a risk of death of 4.6times greater in the powerlifters compared with the control population. This study shows that there may be an association between AAS misuse and premature death (27). Acute myocardial infarction has been reported in AAS usersmainly in the form of case reports (28).

From this in-depth literature review, it is evident that AAS use is linked with adverse effects on the cardiovascular system. There appears to be a gap in the literature regarding the specific knowledge and awareness of sports participants, team coaches, doctors and gym instructors about the harmful effects of AAS. The main purpose of this study was to further evaluate the awareness and attitudes of amateur sports participants about the cardiac risks associated with anabolic steroid use.

\section{Methods}

This study is a cross-sectional, observational study using an anonymous online questionnaire. The inclusion criteria included male or female, 18 years or greater and currently a member of the National University of Ireland Galway (NUIG) sports club. This specific population was chosen because these people are mostly likely to come across PED in their training. The author and supervisor in collaboration developed a nonvalidated thirty-one-question survey.Expert advice for development of the questionnaire was sought from an expert researcher, who holds a $\mathrm{PhD}$ in Sports Science, and his recommendations were incorporated into the questionnaire. The questionnaire was piloted for its use ona group of 10 students. Verbal feedback was obtained from them regarding the comprehensibility and readability of the questionnaire. The average time taken to fill out the questionnaire was also recorded and this figure was reported in the participant information sheet.

The questionnaire was designed via Survey Monkey (www.surveymonkey.com), and included the participant information sheet and consent form. The NUIG sports development officer was asked to senda link of the questionnaire to all current members of NUIG sports clubs. A reminder email was distributed at the midway point to encourage completion for those that had not filled it and to acknowledge those that had.The surveyconsisted of information on demographics including gender, age and sports played. Participants were asked about how often they engaged in weight-training exercise per week and how important nutrition is to their performance.Closed, yes or no questions were asked about the current use of AAS and other PED.Participants were asked to agree or disagree on numerousstatements that were included to ascertain the participants' level of knowledge regarding the cardiac effects of AAS use.

Sports participants may not be in communication with the correct sources regarding nutritional advice and information of the health effects of various PED.Internet sites that sell PED may not appropriately include the side effects associated with their use. This specific concern was addressed in the questionnaire. The other questions were related to the attitudes regarding the use of AAS and other PED. The participants were requested to agree or disagree on various statements about attitudes to the use of PED. The results of the questionnaire were collected on Survey Monkey and imported to a statistical analysis package called SPSS version 21. Descriptive statistics such as percentage, standard deviation, mean and median wasused. Correlational analysisusing Chi-Square test wasperformed to show significant differences between knowledge of side effects, sports played and gender. This study received ethical committee approval by the National University of Ireland, Galway.

\section{Results}

A total of 267 participants were invited to complete the online survey monkey questionnaire. 54 respondents returned a completed questionnaire giving a response rate of 20\%. 35 (64.8\%) of the participants were male and the mean age was 21.6 years. Out of all the participants $59 \%$ had never been advised about the adverse effects of ASS and 33\% personally knew somebody that uses them. With regards nutritional supplements $35 \%$ consume whey protein, $11 \%$ creatine and $11 \%$ amino acids. $94 \%$ of respondents felt that nutrition was either important or essential to sports performance. The respondents engaged in a variety of sports including: rowing $(25.9 \%)$, soccer $(7.4 \%)$, athletics $(3.7 \%)$, rugby $(3.7 \%)$, hurling, football, cricket, weight lifting, swimming, martial arts, judo, taekwondo and surfing.

When specifically asked about the cardiac effects of AAS, 65\% agreed that AAS use could increase heart muscle mass that may adversely affect it function, 59\% agreed that it can adversely affect blood pressure and $69 \%$ agreed that it can give rise to abnormal heart rhythms. $26 \%$ of respondents agreed that AAS use could increase blood cholesterol levels and $70 \%$ agreed that PEDs are used to gain muscle mass quicker.

$76 \%$ of respondents felt people should be taught in schools about the adverse effects of PEDs and $93 \%$ agreed that coaches should warn their players about their harmful effects. $22 \%$ of participants felt that if people were aware of the health effects of anabolic steroids, they would not take them. Only $13 \%$ of individuals felt that it is acceptable to use muscle-enhancing drugs if you do not compete in sports that require muscle strength. $41 \%$ felt it is acceptable to use muscle-enhancing drugs if a doctor supervises their use. $24 \%$ felt using muscleenhancing drugs is a personal matter and $26 \%$ agreed that it is easy to obtain anabolic steroids for personal use 
in Ireland. Participants when asked about other effects of AAS use, answers such as: impotence, infertility, testicular atrophy, mood disturbances and aggression were listed.

\section{Discussion}

This research study represents the first survey to question amateur sports participants in Ireland regarding the knowledge and awareness of the cardiac risks associated with AAS. The data revealed that $59 \%$ of sports participants have never been advised about the health effects of anabolic steroids. This shows that the majority of people are not well prepared to understand the health risks associated with AAS. AAS have been a banned class of drugs by International Olympic Committee since 1974, and therefore more widespread knowledge about their effects is important (29).

The estimated lifetime prevalence of AAS use in Ireland is $2 \%$, however this figure is likely underestimated.The questionnaire reveals that one-third of respondents personally know someone that uses AAS, indicating a prevalence that maybe higher than reported. Previous studies in US college students reveal a lifetime prevalence of between 1-3.3\%(30-35).

A study performed on competitive male and female bodybuilders in the United States showed an alarming 54\% male and $10 \%$ female steroid users. The main reason for its use was their belief that steroid use would be an important factor in order to win competitions (36). Another study carried out on adolescents in an American high school revealed a 2.7\% prevalence of AAS use. The prevalence appeared to be higher in sports participants than in non-participants. This study also demonstratedthat $18 \%$ of users that were informed about the risks of AAS (34). As a result health care providers, gym trainers and coaches should be more aware of the side effects of AAS and should be able to relay this information to their players/patients.

It is unsurprising that Internet sites are the preferred primary source for obtaining information about nutrition in relation to weight lifting. TheseInternetsources of advice or purchase of AAS may be unregulated and not entirely accurate. Studies have shown that Internet or other illicit purchase of AAS have shown inaccurate information about what is exactly inside these substances $(37,38)$.Approximately half of the Internet sites advocate their safe use and less than 5\% of the sites presented health risk information about their use(39). Friends are the second most popular source of information, which may also be receiving their nutritional weight lifting information from the Internet. It is easy to see how peer influences might have an effect on people's choice regarding potential nutritional substances. Gym trainers were the third source of such information; however one should expect this number to be greater. The question arises whether or not gym trainers are appropriately trained to give nutritional advice about weight training. Nutrition shops and doctors/pharmacists are also surprisingly low. This is in keeping with a study that demonstrated that $40 \%$ of AAS users trusted information given to them about AAS from their drug dealer and 56\% of users have never revealed or discussed its use with a medical professional (40). Perhaps we would like to see more doctor/pharmacist and gym trainer advice, and less friends and Internet advice.Many team physicians and sports medicine practitioners are unfamiliar with the benefits and risks of PEDs and thus are unable to educate young athletes on this topic (41). There would not be a need to turn to friends or Internet if there were formal channels through their team leader/coach that would provide more reliable sources of advice in written form. A recent study shows similar results that steroid users obtain information about the use, effects and route of administration of AAS from peer users within the gym and from the Internet (42).

Nutrition is certainly important for muscle mass building and this was displayed in the survey where $94 \%$ of respondents felt nutrition was important or essential for sports performance. The American College of Sports Medicine agrees that physical activity, athletic performance, and recovery from exercise are enhanced by optimal nutrition (43). PEDs such as creatine and whey protein are also becoming increasing popular. There is a lack of regulation of the manner in which these products are sold and supplied with many available over the Internet. This has led to concerns that many products that are purchased over the Internet may have contaminants including AAS and human growth hormone (44). Over half of the individuals report not using any nutritional supplements; they however may eat a diet that is high in protein. Interestingly, only $46 \%$ of individuals in the questionnaire reported use of either supplemental whey protein or amino acids. $11 \%$ used creatine for muscle building, which is a legal performance enhancing substance that helps in promoting quicker muscle recovery. There are dangers in contamination of pure creatine with other substances such as ephedrine or AAS, especially when purchased over the Internet because these substances are not adequately regulated. The questionnaire reported no use of ephedrine or erythropoietin for muscle building. This is perhaps due to lack of cyclists, runners and other endurance sports in the sample population.

In the questionnaire, respondents had better knowledge than anticipated about the cardiac effects of AAS use. Between 59\% and $72 \%$ of the participants were aware that AAS use can elevate blood pressure, increase heart muscle mass, may lead to development of abnormal cardiac rhythms and may adversely affect cardiac pump function. It is possible that the question was phrased in a leading fashion and may have encouraged participants to agree with the statements.Regardless of potential lead bias, the awareness of these 
effects are still not entirely perfect since a sizeable minority between $28-41 \%$ of participants were not aware of these effects. In our sample population, no participant reports to currently using AAS so it would not be unreasonable for them to know about these adverse effects, despite 59\% of respondents never been previously advised about their side effects. It is reassuring to see that approximately two-thirds of respondents are aware of these effects; however, it is somewhat worrying to see that approximately one third are not aware of these potentially life-threatening effects. The overall awareness rates of AAS are low in other studies and a history of athletic performance increases the risk of consumption (35). The sports participants included in this survey are all educated amateur athletes, therefore one would expect them to be more aware of the side effects of AAS use. This information clearly highlights that there is a need for educational efforts to increase knowledge and awareness of these substances. However a previous study showed that an anabolic steroid education program of high school football players showed no difference in attitudes compared to controls, even despite increased knowledge (45).

However a low number, 26\%, were aware that ASS use could increase serum cholesterol levels.In university or college, the majority of individuals may not be aware of their own cholesterol levels. Therefore, it may not be surprising that $74 \%$ of individuals were not informed about the cholesterol effects of AAS use. Cholesterol levels are not at the forefront of amateur athletes' minds, however perhaps if they were informed about the long-term end organ effects, they may take this more seriously. As part of an educational effort it is important for emphasis to be put on these cholesterol effects of AAS use.

When asked about AAS use, none of the respondents were current users. However $3.7 \%$ of participants had previously used AAS, which at a national scale would represent a large number of individuals. This number would be slightly less than previous reported studies in the US. There are limitations to this number because it relies on individuals being honest and accurately self-reporting drug use, however this number seems to be consistent across different studies. Individuals may lack full confidence in the anonymity of the questionnaire and these data must not be taken as entirely accurate as a result. It is notoriously difficult to obtain reliable information from people about drugs that have some kind of illegality, although the illegal component refers to elite athletes. The illegality related to a gym user would be if the substances were illegally imported or purchased from the Internet. This is because AAS is not available for legal purchase in Ireland. A large burden of AAS use would likely be in the college or university amateur athlete population where people are not tested.

(Figure 1, 2, 3 and 4 of the results section are attached at end of document)

\section{Public health educational efforts}

As expected, only $11 \%$ of individuals were given information about the health risks of PEDs when they joined the university sports club. This is a situation that needs to change. The vast majority of respondents feel that people should be taught in schools about the adverse effects of anabolic steroid use. School-based interventions to prevent AAS use among high-risk adolescent athletes have shown significant beneficial effects, including better knowledge of alternatives to steroid use and less likely to want to use them even if their friends used them $(46,47)$. Only a very small number, $3.7 \%$, mentioned that gyms warn their clients about potential risks associated with AAS use. 94\% of the survey participant's felt that coaches play a pivotal role in warning their players of the adverse effects of AAS.Clearly there is an expanded role for the gym fitness instructor to learn about these substances, since they will be a primary source of contact for such information. These instructors can either point individuals towards sources of more research evidence that is health protecting or direct individuals to PEDs use. For example, a flyer could be given to each individual as they sign up to a program detailing healthy methods of muscle building.

Interestingly, when asked whether or not people would consume AAS if they were aware of their health effects, the majority felt that people would continue to use these products despite being aware of their ill effects. This is in contrary to what was demonstrated in school-based intervention model, where individuals were less likely to continue use when they were aware of the adverse effects of AAS (46). This may be due to the intense competitive drive to win competitions at an amateur level. This would be similar to tobacco consumption where individuals are aware of the health consequences, however despite all the public health campaigns, people continue to smoke.

The respondents do not agree for the most part that one should take muscle-enhancing drugs if they are not involved in sports that require muscle strength for competing. However, $13 \%$ of survey participants felt that it is reasonable fornon-competitive sports individuals to use AAS for cosmetic reasons. Interestingly a sizeable minority agrees that it is acceptable for individuals to use AAS if a doctor supervises its use. It has already been highlighted that the doctor or pharmacist is not the preferred source of information about side effects of PEDs. Through rigorous public health awareness campaigns, individuals will be more informed about where to go to receive such information. As a part of this awareness campaign doctors, in particular general practitioners working in the student health unit, should be trained to give advice or information to individuals that may use such muscle-enhancing substances. Sports medicine doctors in Ireland are aware of these side effects mainly 
because the Irish Sport Council has a National Anti-Doping Programme, where their sole priority is to protect Ireland's sporting integrity against the threat of doping. Perhaps knowledge about PEDs and their side effects can be taught in medical school, where it may be implemented into the curriculum.In this manner all graduating medical doctors will be aware and able to answer questions about PEDs from their friends and family.

When specifically looking at the autonomy of sports participants, only $24 \%$ of respondents felt that the use of muscle-enhancing drugs is a personal matter. Health implications secondary to PEDs would certainly become a burden on the health service. Individuals may develop health effects that may affect their families and cause unnecessary economic and financial strains. The questionnaire respondents feel that the decision to consume PEDs is not entirely to the individual concerned but their immediate and societal surroundings must also play a role. Individuals when making up their own mind about use of these substances need to be informed about side effects, and it is clear from this survey that there is a lack of informed decision-making amongst sports participants. The exact jurisdiction of who should be giving advice about PEDs is unclear, however from the survey the respondents feel that individuals are more likely to get information from their friends or gym trainers, but also agree that this information should be taught in schools. $26 \%$ of respondents feel that it is easy to obtain AAS for personal use in Ireland. These substances can easily be purchased over the Internet and therefore access to such substances will not be an obstacle. Black-market sales, which exceed 100 million dollars every year, are a big source for obtaining PEDs (41).This is the reason why PEDs are getting into the hands of sports participants, which also include information naive adolescents. Other sources to obtain AAS may include unethical healthcare professionals and team physicians who are interested in making financial profit. A large survey studying the substance use of college student-athletes has shown that $32.1 \%$ obtained their AAS from a physician other than the institution's team physician (48).

There is unprompted awareness of the other extra-cardiac complications of anabolic steroids use that are very much linked to body image such as sexual potency, fertility, acne and testicular atrophy. In giving advice about the cardiac effects of AAS, it may be useful to also emphasisesome of the non-cardiac effects because they may resonate more with a university student audience. It may be that AAS are associated in the press with certain psychological effects, such as aggression and mood disturbance, but the cardiac effects are not frequently highlighted.

Apart from sports medicine doctors and team coaches, there is a role for increased awareness amongst psychiatrists. Psychiatric doctors may have patients that abuse AAS since they are known to cause increased aggression, personality disorders, psychosis and mood disorders (1). Studies have shown that AAS dependence is a valid diagnostic entity, and is a growing public health concern. Researchers feel that AAS share common brain mechanisms with other forms of substance dependence, especially opioid dependence (49). AAS use may be a 'gateway' to other addictions. Psychiatrist's need to vigilant in recognising substance misuse, since users are often reluctant to reveal its use and seek treatment (50).

\section{Conclusion}

AAS is a health risk not only to the cardiovascular system but also to other organ systems. Although some of their adverse effects appear to be reversible with cessationof the substance used. This study shows an obvious lack of awareness and knowledge about the health risks of AAS use amongst competitive athlete members of university sports teams. The low response rate reduces the generalisability of the findings in this survey study; however, useful trends are observed which would benefit from further study. This study prompts suggestions for further work in this area, perhaps a doctoral research study with a larger sample population. It also allows for the need to develop recommendations around how public health information should be targeted to sports participants.

\section{References}

[1]. Hartgens F, Kuipers H. Effects of androgenic-anabolic steroids in athletes. Sports medicine. 2004;34(8):513-54.

[2]. Payne JR, Kotwinski PJ, Montgomery HE. Cardiac effects of anabolic steroids. Heart. 2004;90(5):473-5.

[3]. Todd T. Anabolic steroids: the gremlins of sport. Journal of sport history. 1987;14(1):87-107.

[4]. Yesalis CE, Anderson WA, Buckley WE, Wright JE. Incidence of the nonmedical use of anabolic-androgenic steroids. NIDA research monograph. 1990;102:97-112.

[5]. Silver MD. Use of Ergogenic Aids by Athletes. Journal of the American Academy of Orthopaedic Surgeons. 2001;9(1):61-70.

[6]. Lindstrom M, Nilsson AL, Katzman PL, Janzon L, Dymling JF. Use of anabolic-androgenic steroids among body builders Frequency and attitudes. Journal of Internal Medicine. 1990;227(6):407-11.

[7]. Stilger VG, Yesalis CE. Anabolic-androgenic steroid use among high school football players. Journal of Community Health. 1999;24(2):131-45.

[8]. Hoberman JM, Yesalis CE. The history of synthetic testosterone. Scientific American. 1995;272(2):76-81

[9]. Basaria S, Wahlstrom JT, Dobs AS. Clinical review 138: Anabolic-androgenic steroid therapy in the treatment of chronic diseases. The Journal of clinical endocrinology and metabolism. 2001;86(11):5108-17.

[10]. Pan L, Wang M, Xie X, Du C, Guo Y. Effects of Anabolic Steroids on Chronic Obstructive Pulmonary Disease: A Meta-Analysis of Randomised Controlled Trials. PLoS ONE. 2014;9(1):e84855.

[11]. Lenders JW, Demacker PN, Vos JA, Jansen PL, Hoitsma AJ, van 't Laar A, et al. Deleterious effects of anabolic steroids on serum lipoproteins, blood pressure, and liver function in amateur body builders. International journal of sports medicine. 1988;9(1):19-23. 
[12]. Kuipers H, Wijnen JA, Hartgens F, Willems SM. Influence of anabolic steroids on body composition, blood pressure, lipid profile and liver functions in body builders. International journal of sports medicine. 1991;12(4):413-8.

[13]. Palatini P, Giada F, Garavelli G, Sinisi F, Mario L, Michieletto M, et al. Cardiovascular effects of anabolic steroids in weighttrained subjects. Journal of clinical pharmacology. 1996;36(12):1132-40.

[14]. Sader MA, Griffiths KA, McCredie RJ, Handelsman DJ, Celermajer DS. Androgenic anabolic steroids and arterial structure and function in male bodybuilders. Journal of the American College of Cardiology. 2001;37(1):224-30.

[15]. Hartgens F, Cheriex EC, Kuipers H. Prospective echocardiographic assessment of androgenic-anabolic steroids effects on cardiac structure and function in strength athletes. International journal of sports medicine. 2003;24(5):344-51.

[16]. Perk J, De Backer G, Gohlke H, Graham I, Reiner Z, Verschuren WM, et al. [European Guidelines on Cardiovascular Disease Prevention in Clinical Practice (version 2012). The Fifth Joint Task Force of the European Society of Cardiology and other societies on cardiovascular disease prevention in clinical practice (constituted by representatives of nine societies and by invited experts)]. Giornale italiano di cardiologia (2006). 2013;14(5):328-92.

[17]. Gordon DJ, Probstfield JL, Garrison RJ, Neaton JD, Castelli WP, Knoke JD, et al. High-density lipoprotein cholesterol and cardiovascular disease. Four prospective American studies. Circulation. 1989;79(1):8-15.

[18]. Glazer G. Atherogenic effects of anabolic steroids on serum lipid levels. A literature review. Archives of internal medicine. 1991;151(10):1925-33

[19]. Applebaum-Bowden D, Haffner SM, Hazzard WR. The dyslipoproteinemia of anabolic steroid therapy: increase in hepatic triglyceride lipase precedes the decrease in high density lipoprotein2 cholesterol. Metabolism: clinical and experimental. 1987;36(10):949-52.

[20]. Harjai KJ. Potential new cardiovascular risk factors: Left ventricular hypertrophy, homocysteine, lipoprotein(a), triglycerides, oxidative stress, and fibrinogen. Annals of Internal Medicine. 1999;131(5):376-86.

[21]. Marsh JD, Lehmann MH, Ritchie RH, Gwathmey JK, Green GE, Schiebinger RJ. Androgen receptors mediate hypertrophy in cardiac myocytes. Circulation. 1998;98(3):256-61.

[22]. Sharma S. Athlete's heart - Effect of age, sex, ethnicity and sporting discipline. Experimental Physiology. 2003;88(5):665-9.

[23]. Karila TAM, Karjalainen JE, Mäntysaari MJ, Viitasalo MT, Seppälä TA. Anabolic androgenic steroids produce dose-dependent increase in left ventricular mass in power athletes, and this effect is potentiated by concomitant use of growth hormone. International journal of sports medicine. 2003;24(5):337-43

[24]. Krieg A, Scharhag J, Albers T, Kindermann W, Urhausen A. Cardiac tissue doppler in steroid users. International journal of sports medicine. 2007;28(8):638-43.

[25]. Hajimoradi B, Kazerani H. Echocardiographic findings in power athletes abusing anabolic androgenic steroids. Asian Journal of Sports Medicine. 2013;4(1):10-4

[26]. Urhausen A, Albers T, Kindermann W. Are the cardiac effects of anabolic steroid abuse in strength athletes reversible? Heart. 2004;90(5):496-501.

[27]. Pärssinen M, Kujala U, Vartiainen E, Sarna S, Seppälä T. Increased premature mortality of competitive powerlifters suspected to have used anabolic agents. International journal of sports medicine. 2000;21(3):225-7.

[28]. Wysoczanski M, Rachko M, Bergmann SR. Acute myocardial infarction in a young man using anabolic steroids. Angiology. 2008;59(3):376-8

[29]. Kicman AT, Gower DB. Anabolic steroids in sport: biochemical, clinical and analytical perspectives. Annals of clinical biochemistry. 2003;40(Pt 4):321-56.

[30]. McCabe SE, Brower KJ, West BT, Nelson TF, Wechsler H. Trends in non-medical use of anabolic steroids by U.S. college students: results from four national surveys. Drug Alcohol Depend. 2007;90(2-3):243-51.

[31]. Presley CAMPWLRCJRSIUCICIL. Alcohol and Drugs on American College Campuses: Use, Consequences, and Perceptions of the Campus Environment, Volume III: 1991-93. United States1996.

[32]. Meilman PW, Crace RK, Presley CA, Lyerla R. Beyond performance enhancement: polypharmacy among collegiate users of steroids. Journal of American college health : J of ACH. 1995;44(3):98-104.

[33]. Tuttle LD, Gaa GL, Griffith EH, Cahill BR. Prevalence of anabolic steroid use among illinois high school students1994. 216-22 p.

[34]. Tanner SM, Miller DW, Alongi C. Anabolic steroid use by adolescents: Prevalence, motives, and knowledge of risks. Clinical Journal of Sport Medicine. 1995;5(2):108-15.

[35]. Fayyazi Bordbar MR, Abdollahian E, Samadi R, Dolatabadi H. Frequency of Use, Awareness, and Attitudes Toward Side Effects of Anabolic-Androgenic Steroids Consumption Among Male Medical Students in Iran. Substance use \& misuse. 2014

[36]. Tricker R, O'Neill MR, Cook D. The incidence of anabolic steroid use among competitive bodybuilders. Journal of drug education. 1989;19(4):313-25.

[37]. Evans-Brown M, Kimergård A, McVeigh J. Elephant in the room? The methodological implications for public health research of performance-enhancing drugs derived from the illicit market. Drug Testing and Analysis. 2009;1(7):323-6.

[38]. Kimergård A, McVeigh J, Knutsson S, Breindahl T, Stensballe A. Online marketing of synthetic peptide hormones: poor manufacturing, user safety, and challenges to public health. Drug Testing and Analysis. 2014;6(4):396-8.

[39]. Clement CL, Marlowe DB, Patapis NS, Festinger DS, Forman RF. Nonprescription steroids on the Internet. Subst Use Misuse. 2012;47(3):329-41.

[40]. Pope HG, Kanayama G, Ionescu-Pioggia M, Hudson JI. Anabolic steroid users' attitudes towards physicians. Addiction (Abingdon, England). 2004;99(9):1189-94.

[41]. Tokish JM, Kocher MS, Hawkins RJ. Ergogenic Aids: A Review of Basic Science, Performance, Side Effects, and Status in Sports. The American Journal of Sports Medicine. 2004;32(6):1543-53.

[42]. Kimergård A, McVeigh J. Environments, risk and health harms: a qualitative investigation into the illicit use of anabolic steroids among people using harm reduction services in the UK. BMJ Open. 2014;4(6).

[43]. Rodriguez NR, Di Marco NM, Langley S. American College of Sports Medicine position stand. Nutrition and athletic performance. Med Sci Sports Exerc. 2009;41(3):709-31.

[44]. Geyer H, Parr MK, Mareck U, Reinhart U, Schrader Y, Schänzer W. Analysis of Non-Hormonal Nutritional Supplements for Anabolic-Androgenic Steroids - Results of an International Study. International journal of sports medicine. 2004;25(2):124-9.

[45]. Goldberg L, Bosworth EE, Bents RT, Trevisan L. Effect of an anabolic steroid education program on knowledge and attitudes of high school football players. Journal of adolescent health care : official publication of the Society for Adolescent Medicine. 1990;11(3):210-4

[46]. Goldberg L, Elliot DL, Clarke GN, MacKinnon DP, Zoref L, Moe E, et al. The Adolescents Training and Learning to Avoid Steroids (ATLAS) prevention program. Background and results of a model intervention. Archives of pediatrics \& adolescent medicine. 1996;150(7):713-21 
[47]. Goldberg L, Elliot D, Clarke GN, MacKinnon DP, Moe E, Zoref L, et al. Effects of a multidimensional anabolic steroid prevention intervention. The Adolescents Training and Learning to Avoid Steroids (ATLAS) Program. JAMA : the journal of the American Medical Association. 1996;276(19):1555-62.

[48]. Green GA, Uryasz FD, Petr TA, Bray CD. NCAA study of substance use and abuse habits of college student-athletes. Clinical journal of sport medicine : official journal of the Canadian Academy of Sport Medicine. 2001;11(1):51-6.

[49]. Kanayama G, Brower KJ, Wood RI, Hudson JI, Pope HG, Jr. Anabolic-androgenic steroid dependence: an emerging disorder. Addiction (Abingdon, England). 2009;104(12):1966-78.

[50]. Rashid H, Ormerod S, Day E. Anabolic androgenic steroids: what the psychiatrist needs to know. Advances in Psychiatric Treatment. 2007;13(3):203-11.

\section{Results figures:}

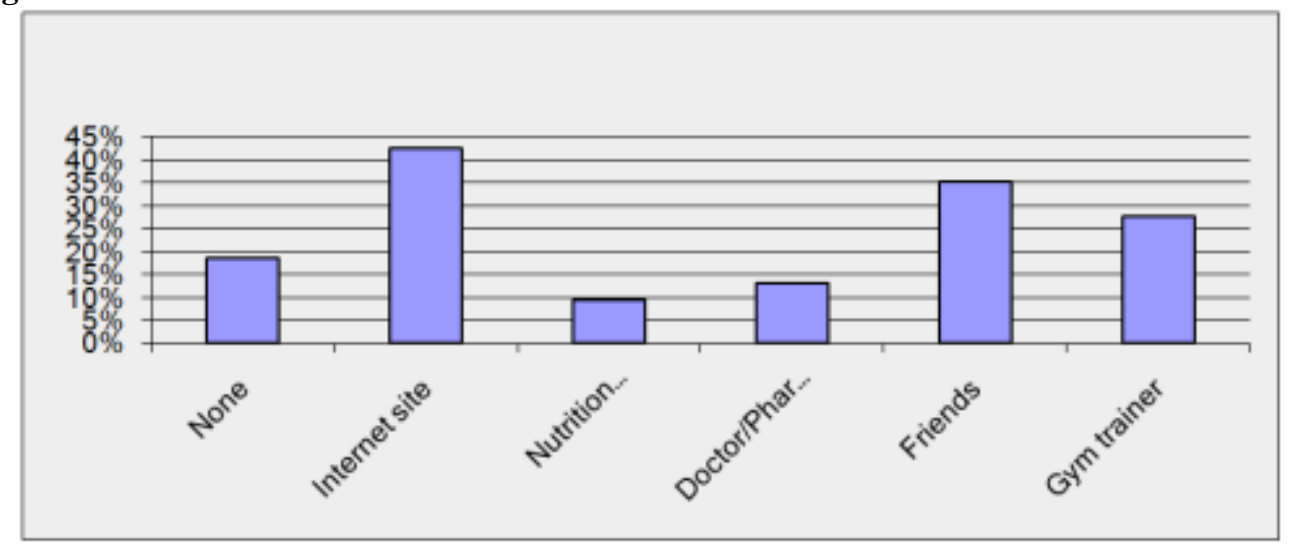

Figure 1: Where do you receive your preferred nutritional advice in relation to weight lifting?
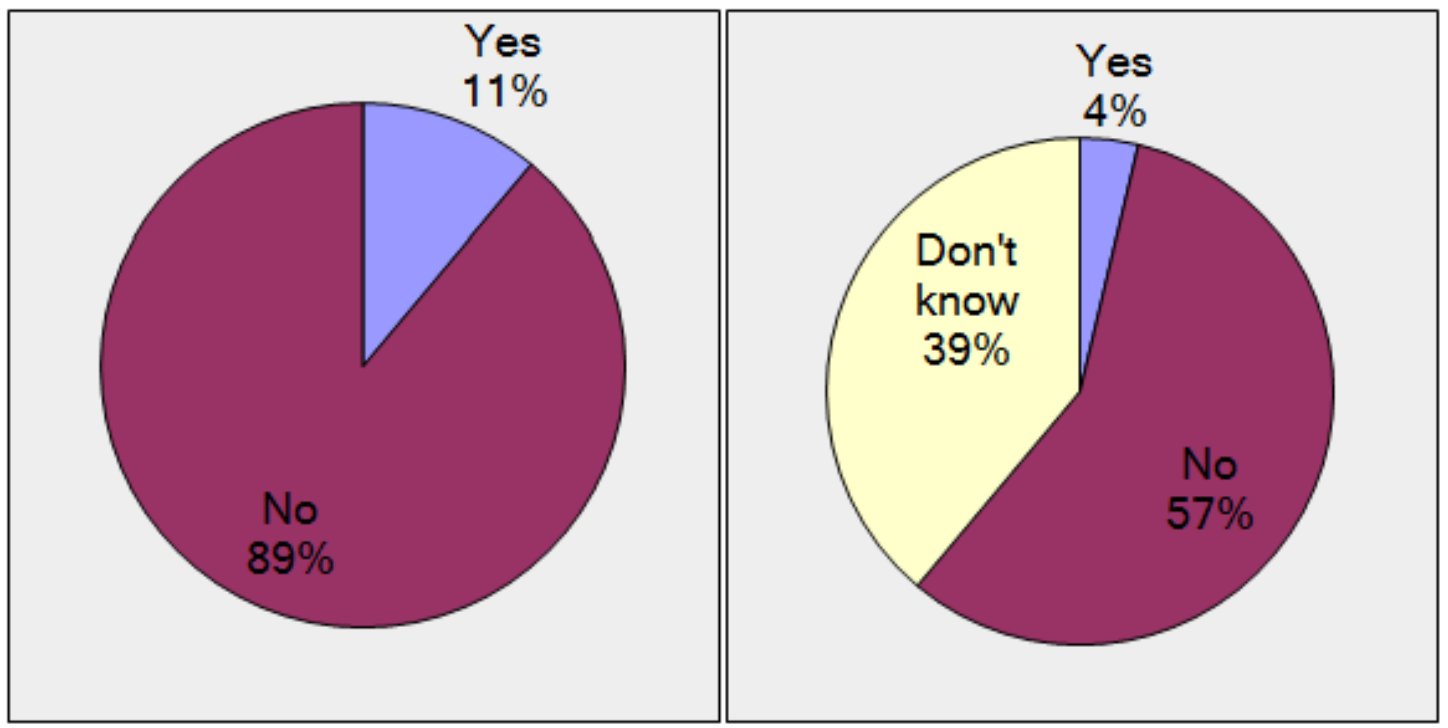

Figure 2: Were you given any information about the health risks of performance enhancing drugs when joining your University sports club?(left panel)

Figure 3:Do gyms warn their clients of the potential risks of anabolic steroids?(right panel) 


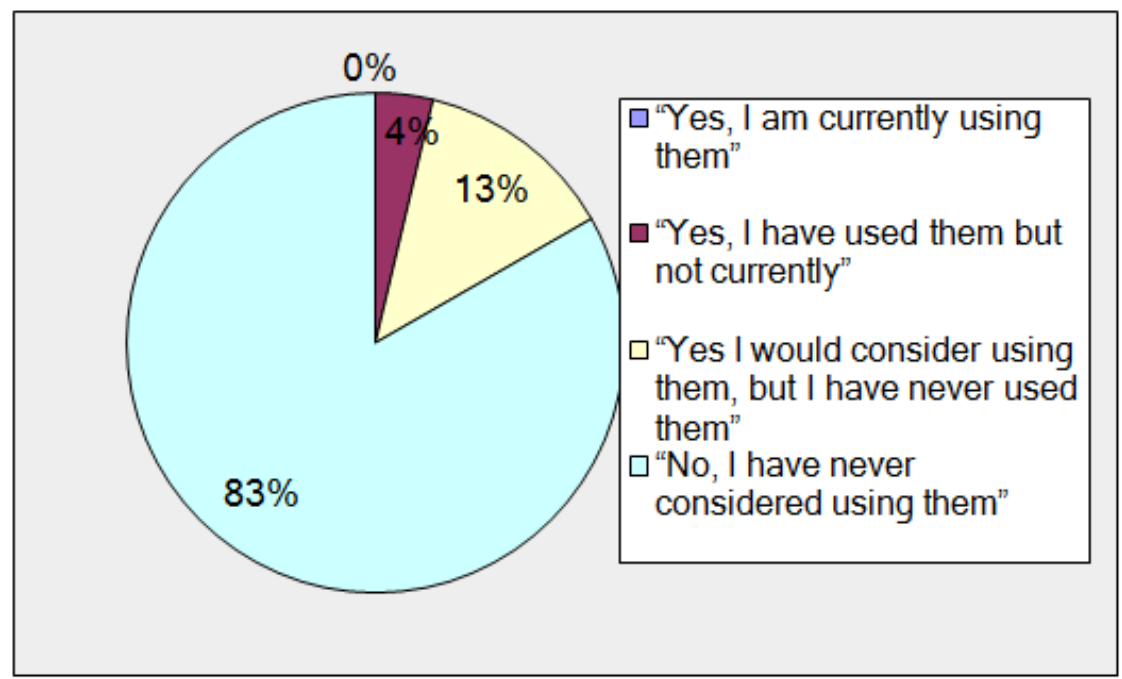

Figure 4: Have you ever used or would you consider using muscle-enhancing drugs/anabolic steroids? 